\title{
Risk factors for the development of hepatocellular carcinoma (HCC) in chronic hepatitis B virus (HBV) infection: a systematic review and meta-analysis
}

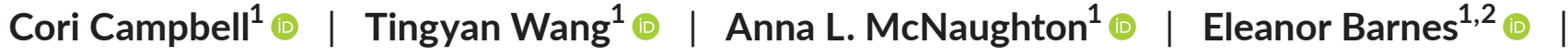 \\ Philippa C. Matthews ${ }^{1,3,4}$ (])
}

${ }^{1}$ Nuffield Department of Medicine, University of Oxford, Oxford, UK

${ }^{2}$ Department of Hepatology, Oxford University NHS Foundation Trust, John Radcliffe Hospital, Oxford, UK

${ }^{3}$ Department of Infectious Diseases and Microbiology, Oxford University Hospitals NHS Foundation Trust, John Radcliffe Hospital, Oxford, UK

${ }^{4}$ NIHR BRC, John Radcliffe Hospital, Oxford, UK

\section{Correspondence}

Philippa C. Matthews, Nuffield Department of Medicine, University of Oxford, Medawar Building, South Parks Road, Oxford OX1 3SY, UK.

Funding information

GlaxoSmithKline (funding to CC). Wellcome funding (grant ref. 110110/Z/15/Z to PCM).

\begin{abstract}
Hepatocellular carcinoma ( $\mathrm{HCC}$ ) is one of the leading contributors to cancer mortality worldwide and is a leading cause of death in individuals with chronic hepatitis B virus (HBV) infection. It is uncertain how the presence of other metabolic factors and comorbidities influences HCC risk in HBV. Therefore, we performed a systematic literature review and meta-analysis to seek evidence for significant associations. MEDLINE, EMBASE and Web of Science databases were searched from 1 January 2000 to 24 June 2020 for studies investigating associations of metabolic factors and comorbidities with HCC risk in individuals with chronic HBV infection, written in English. We extracted data for meta-analysis and generated pooled effect estimates from a fixedeffects model. Pooled estimates from a random-effects model were also generated if significant heterogeneity was present. We identified 40 observational studies reporting on associations of diabetes mellitus (DM), hypertension, dyslipidaemia and obesity with HCC risk. Only DM had a sufficient number of studies for meta-analysis. DM was associated with $>25 \%$ increase in hazards of HCC (fixed-effects hazards ratio [HR] 1.26, 95\% confidence interval $(\mathrm{Cl}) 1.20-1.32$, random-effects $H R 1.36,95 \% \mathrm{Cl}$ 1.23-1.49). This association was attenuated towards the null in a sensitivity analysis restricted to studies adjusted for metformin use. In conclusion, in adults with chronic HBV infection, DM is a significant risk factor for HCC, but further investigation of the influence of antidiabetic drug use and glycaemic control on this association is needed. Enhanced screening of individuals with $\mathrm{HBV}$ and diabetes may be warranted.
\end{abstract}

\section{KEYWORDS}

comorbidities, diabetes, HCC, Hepatitis B virus, hepatocellular carcinoma

\section{1 | INTRODUCTION}

Hepatitis B virus (HBV) is a hepatotropic virus responsible for substantial morbidity and mortality worldwide. Infection can be acute or chronic, with most of the HBV disease burden attributable to chronic disease.
The World Health Organization (WHO) estimated a chronic HBV (CHB) global burden of 257 million CHB-infected individuals for 2015, with $887,000 \mathrm{HBV}$-attributable deaths reported in the same year, ${ }^{1}$ making HBV one of the leading causes of morbidity and mortality from viral infection, for which the burden has increased in recent decades. ${ }^{2}$ 
$\mathrm{CHB}$ deathsdue to primary liver cancer and cirrhosis account for the majority of deaths attributable to viral hepatitis. A Global Burden of Disease study on the global hepatocellular carcinoma (HCC) burden reported a $42 \%$ increase in incident cases of HCC attributable to CHB infection between 1990 and 2015, ${ }^{3}$ among which CHB infection was the largest contributor, responsible for more than $30 \%$ of incident cases in $2015 .^{3}$

Multiple risk factors for $\mathrm{HCC}$ in $\mathrm{CHB}$-infected individuals have been established, including sex, age, cirrhosis and co-infection with human immunodeficiency virus (HIV) or other hepatitis viruses (including hepatitis $C$ and D). Previous studies have investigated associations of comorbidities, such as diabetes mellitus $(D M)^{4-7}$ and hypertension, ${ }^{8,9}$ with risk of HCC in the general population, and The European Association for the Study of the Liver (EASL) recognizes $\mathrm{DM}$ as a risk factor for $\mathrm{HCC}$ in $\mathrm{CHB} .{ }^{10}$ As the global prevalence of comorbidities such as $\mathrm{DM},{ }^{11}$ renal disease, ${ }^{12}$ hypertension ${ }^{13}$ and coronary heart disease $(\mathrm{CHD})^{14}$ continues to rise, these conditions are increasingly relevant to the development of HCC.

Various risk scores have been developed to predict HCC risk: the PAGE-B risk score was developed to predict $\mathrm{HCC}$ risk in Caucasian patients on antiviral treatment, ${ }^{15}$ while the REACH-B, ${ }^{16,17}$ GAG-HCC ${ }^{18,19}$ and $\mathrm{CU}-\mathrm{HCC}^{18,20-22}$ risk scores apply to untreated Asian populations. Existing risk scores use age, sex and HBV DNA viral load (VL) to predict risk. CU-HCC and GAG-HCC include parameters for cirrhosis; however, no score accounts for comorbidities such as DM or hypertension. It is possible that risk prediction could be improved by incorporating these comorbid conditions.

Despite rises in the global prevalence of relevant comorbidities, evidence concerning associations of comorbidities with $\mathrm{HCC}$ risk in $\mathrm{CHB}$ is poor and heterogeneous. Neither EASL, the American Association of the Study of Liver Disease (AASLD) ${ }^{23}$ nor the Asian Pacific Association for the Study of the Liver (APASL) ${ }^{24}$ guidelines for HBV management include recommendations for enhanced screening or DM management in $\mathrm{CHB}$, despite recent clinical interest in the potential utility of metformin in preventing and treating various cancers. ${ }^{25,26}$ Furthermore, there are few studies investigating associations of other potentially relevant comorbidities (such as hypertension, CHD and renal disease) and their metabolic risk factors (such as obesity and dyslipidaemia) with $\mathrm{HCC}$ risk. Therefore, we undertook a systematic review, aiming to summarize and critically appraise studies investigating associations of relevant comorbidities and metabolic factors with risk of HCC in CHB-infected individuals.

\section{2 | METHODS}

\subsection{Search strategy and selection criteria}

In June 2020, we systematically searched three databases (Web of Science, EMBASE and MEDLINE) in accordance with PRISMA guidelines ${ }^{27}$; search terms are listed in Table S1. We searched all databases from 1 January 2000 until 24 June 2020, without application of any restrictions for study design applied to search terms or results, but including only full-text human studies published in English.

We combined and deduplicated search results from the three databases, prior to screening for eligibility. We excluded articles not investigating associations of comorbidities with risk of HCC and/ or not restricted to CHB-infected participants. We also searched reference lists of relevant systematic reviews/meta-analyses and studies identified for inclusion to identify additional studies for inclusion. Search terms were constructed and agreed on by three authors (PM, TW and CC) and articles were screened and selected by one author (CC).

\subsection{Data extraction and statistical analysis}

One author (CC) extracted the following summary characteristics from included studies: country, publication year, study design, follow-up period, comorbidities investigated, number of participants, number of HCC cases, sex, age at baseline, risk ratio and covariates adjusted for.

We carried out meta-analysis in $\mathrm{R}$ (version 3.5.1) using the 'meta' package (version 4.12-0), ${ }^{28}$ including only hazard ratios (HRs) minimally adjusting for age and sex reported in cohort or nested case-control studies. We calculated pooled summary effect estimates using the inverse-variance weighting of HRs on the natural logarithmic scale, and quantified between-study heterogeneity using the $\mathrm{I}^{2}$ statistic; significance of heterogeneity was investigated using Cochran's $Q$ test ( $p$ threshold $=0.05$ ). Where $I^{2}$ was $>0$ and heterogeneity was significant, we present both fixed- and random-effects summary estimates. We undertook multiple sensitivity analyses whereby analyses were restricted to studies adjusting for various additional confounders and for DM treatment, and stratified by DM type, in order to investigate robustness of observed associations.

\section{3 | Definitions}

For DM, we considered diagnoses of type 1 and type 2 DM, as well as unspecified DM, for pooling the effect, followed by further stratification by subtypes of diabetes if enough studies were eligible. Hypertension (HT) was defined by either a diagnosis of HT recorded as part of the medical history or current health assessment, or a measurement with mean arterial pressure (MAP) above a specified threshold. Obesity was based on BMI values, by referring to the cut-off in the included studies, where 25,27 and $30 \mathrm{~kg} / \mathrm{m}^{2}$ were the common threshold values used. Cardiovascular disease (CVD) was defined broadly as an umbrella term including any of the following disease subtypes: 
ischaemic heart disease (IHD)/coronary heart disease (CHD) and cerebrovascular disease. Dyslipidaemia was defined according to serum lipid concentrations above a certain threshold defined in the primary studies (thresholds may vary depending on healthcare setting).

\subsection{Quality appraisal}

We used the Newcastle-Ottawa Scale (NOS) to assess the quality of nonrandomized studies, including cohort and case-control studies, ${ }^{29}$ judging studies based on points awarded for selection of study groups, comparability of groups and exposure/outcome ascertainment. Studies with scores of $<5,5-7$ and $>7$ points were considered to be of low, sufficient and high quality, respectively.

\section{3 | RESULTS}

\section{1 | Study characteristics}

In total, our search identified 1,814 articles (899 from MEDLINE, 407 from EMBASE and 508 from Web of Science) (Figure 1). After deduplication, 1136 individual articles were screened by title/abstract, from which 140 full texts were identified for full-text assessment. After exclusion of ineligible articles and reference list searching of relevant articles, 40 articles were identified for inclusion in this review. Summary characteristics of included studies are reported in Table S2.

All studies were observational in design, with 33 cohort and seven case-control studies included (Table S2). Thirty-two studies were conducted in Asian countries. Four studies were restricted to male cohorts, and 36 were undertaken in mixed-sex cohorts. All studies recruited participants from health centres, health care or prescription databases, or pre-existing cohorts or cancer screening programmes. All studies were undertaken in adults, with mean/median ages of cohorts ranging between 40 and 65 years in 33 studies. Thirty-three studies investigated DM/insulin resistance/fasting serum glucose, 11 investigated blood hypertension/blood pressure, seven investigated dyslipidaemia, five investigated obesity and cardiovascular disease. Fewer than five studies investigated other factors including renal disease, statin use and use of antidiabetic drugs.

In the 40 studies including 536,456 adults, $>30,500$ HCC events occurred (we are unable to report an exact number, because one study did not report a precise number of $\mathrm{HCC}$ cases $^{30}$ ). Sample sizes of cohort studies varied widely, ranging from 102 to 214,167 (median 3090), with corresponding numbers of HCC cases ranging from seven (arising among 102 participants) to 11,241 (arising among 214,167 participants). Case-control sample sizes ranged from 182 to 6275 (median 1122) with corresponding numbers of HCC cases ranging from 73 (out of 182 participants) and 1105 (out of 6275 participants).

\subsection{Quality assessment}

Among 40 studies, 39 had quality scores $\geq 5$ (Tables S3 and S4). All 33 cohort studies were of sufficient quality with 13 of these being scored as high quality. Six out of seven case-control studies were of sufficient quality and one of poor quality. Inclusion criteria varied widely, and therefore, study populations were heterogeneous. In most studies, exposures and outcomes were ascertained using health assessment, imaging or record linkage. Twenty-three cohort studies and seven case-control studies accounted for age and sex. HCC typically arises after long durations of infection, and therefore, prolonged follow-ups enable the detection of more HCC events; among 23 cohort studies identified, only five cohort studies had lengths of follow-up $\geq 10$ years.

\subsection{Association of diabetes mellitus with HCC risk}

Thirty-six studies investigated the association of DM with risk of $\mathrm{CHB}$ progression to HCC, comprising seven case-control studies (Table 1a) and 29 cohort studies (Table 1b). Four studies were restricted to males and the others included both sexes (Table S2). Mean ages at baseline in all studies were $\geq 40$ years, respectively. Study populations were heterogeneous with variable inclusion criteria, and definitions of DM were not consistent between studies. Four case-control and four cohort studies investigated type $2 \mathrm{DM}$ /insulin resistance, three case-control and seven cohort studies investigated unspecified DM, and one casecontrol and three cohort studies investigated both type 1 and $2 \mathrm{DM}$ as a composite potential risk factor.

Among the seven case-control studies that reported effect estimates there was directional inconsistency between effect estimates, with four studies reporting an increased risk of HCC in those with DM as compared to those without, three studies reporting a decreased risk of HCC in those with DM, and one study failing to provide an effect estimate. Odds ratios (ORs) and HRs $>1$ ranged from 1.35 to 2.04 and all were statistically significant. RRs $<1$ ranged from 0.19 to 0.80 , of which two were statistically significant. Among 28 cohort studies providing effect estimates (27 HRs and 1 OR), there was directional consistency with 27 of the reported RRs $>1$. Effect sizes $>1$ ranged from 1.05 to 6.80 , with 15 RRs being statistically significant. The single RR that was $<1$ was nonsignificant.

Minimal adjustment for confounders differed between case-control and cohort studies. Most case-control studies adjusted for age, sex, HCV coinfection, HIV coinfection and cirrhosis. Twenty cohort studies minimally adjusted for age and sex. Of these, 15 adjusted for $\mathrm{HCV}$ coinfection, 13 for cirrhosis, 12 for antiviral treatment, 10 for HIV coinfection, 9 for alcohol consumption, seven each for HBV viral DNA load and cigarette smoking and 6 for other liver disease (including alcoholic liver disease). Eight studies excluded participants who developed HCC within the first 3 to 12 months of follow-up in their main analyses. One study did so in a sensitivity analysis and found this did not modify associations observed. 
1,814 articles identified

- 899 MEDLINE

- 407 Embase

- $\mathbf{5 0 8}$ Web of Science

678 duplicate articles removed

1,136 articles available for title screening

after deduplication

996 articles excluded via title screening

140 full-text articles assessed for

inclusion

106 articles excluded

55 Abstract/poster only

14 Did not investigate association(s) of comorbidities with progression of $\mathrm{CHB}$ to $\mathrm{HCC}$

13 Did not restrict to $\mathrm{CHB}$-infected participants

11 Cohort not restricted to $\mathrm{CHB}$ patients

$6 \mathrm{HCC}$ not investigated as outcome

5 Systematic review/meta-analysis

2 Review/comment

34 full-text articles inclusion meeting

inclusion criteria

6 articles identified via hand-searching

reference lists of included articles

FIGURE 1 Flow chart of study selection. MEDLINE, EMBASE and Web of Science databases were systematically searched using relevant terms to identify relevant human studies published in English from 1 January 2000 to 24 June 2020

\section{4 | Meta-analysis of cohort studies}

DM was associated with increased hazards of progression to HCC by metaanalysis restricted to HRs minimally adjusted for age and sex (Figure 2).
As there was significant heterogeneity $\left(I^{2}=52 \%, p<0.01\right)$, results from both fixed- and random-effects analyses are presented. In random-effects analysis, the hazards of HCC were $36 \%$ higher (summary HR $1.36 ; 95 \% \mathrm{Cl}$ 1.23-1.49) in those with DM as compared to those without DM. 
TABLE 1 A Effect estimates for case-control studies investigating the association of diabetes mellitus with hepatocellular carcinoma risk in adults with $\mathrm{HBV}$ infection

\begin{tabular}{|c|c|c|c|c|c|c|c|}
\hline $\begin{array}{l}\text { Country, } \\
\text { Author (Year) }\end{array}$ & $\begin{array}{l}\text { Participants, } \\
\text { n }\end{array}$ & $\begin{array}{l}\text { HCC } \\
\text { Cases, } \mathrm{n}\end{array}$ & $\begin{array}{l}\text { Age at baseline, } \\
\text { years }\end{array}$ & Sex (\% male) & Source of controls & $\begin{array}{l}\text { Relative risk } \\
\text { measure }^{\mathrm{a}}\end{array}$ & $\begin{array}{l}\text { Risk ratio ( } 95 \% \\
\text { confidence interval) }\end{array}$ \\
\hline $\begin{array}{c}\text { Taiwan, Shyu } \\
(2019)^{70}\end{array}$ & 5932 & 731 & 40-90 (range) & 56.7 & $\begin{array}{l}\text { Same insurance } \\
\text { database as } \\
\text { cases }\end{array}$ & $\mathrm{aHR}$ & 1.35 (1.16 to 1.57$)$ \\
\hline $\begin{array}{l}\text { US, Kennedy } \\
\qquad(2018)^{33}\end{array}$ & 1101 & 278 & 64 & 78 & $\begin{array}{l}\text { Same clinical data } \\
\text { repository as } \\
\text { cases }\end{array}$ & $\mathrm{aOR}$ & 0.60 (0.40 to 0.90$)$ \\
\hline $\begin{array}{l}\text { China, Li } \\
\qquad(2018)^{71}\end{array}$ & 322 & 112 & $\begin{array}{l}52 \text { (median, } \\
\text { HCC cases), } \\
51 \text { (median, } \\
\text { non-HCC } \\
\text { controls) }\end{array}$ & $\begin{array}{l}18.8 \text { (HCC } \\
\text { cases) } \\
26.2 \text { (non-HCC } \\
\text { controls) }\end{array}$ & Hospital controls & $\mathrm{aOR}$ & 2.04 (1.15 to 5.02$)$ \\
\hline $\begin{array}{l}\text { China, Han } \\
\qquad(2017)^{72}\end{array}$ & 182 & 73 & 56.18 (mean) & 79.1 & Hospital controls & N/A & $\mathrm{N} / \mathrm{A}$ \\
\hline $\begin{array}{l}\text { China, Li } \\
\qquad(2012)^{31}\end{array}$ & 6275 & 1105 & $\begin{array}{l}53.8 \text { (mean, } \\
\text { cases) } \\
44.9 \text { (mean, } \\
\text { controls) }\end{array}$ & $\begin{array}{l}84.7 \text { (cases) } \\
73.8 \text { (controls) }\end{array}$ & Hospital controls & aOR & 0.80 (0.60 to 1.10$)$ \\
\hline $\begin{array}{c}\text { Taiwan, Chao } \\
(2011)^{34}\end{array}$ & 1142 & 124 & $30-65$ & 100 & $\begin{array}{l}\text { Control group is } \\
\text { random sample } \\
\text { of non-HCC } \\
\text { participants } \\
\text { from total } \\
\text { cohort }\end{array}$ & aHR & $\begin{array}{l}\text { Those with homeostasis } \\
\text { model assessment- } \\
\text { insulin resistance } \\
\text { (HOMA-IR, fasting } \\
\text { insulin }(\mu \mathrm{U} / \mathrm{ml}) \mathrm{X} \\
\text { fasting glucose } \\
\text { (mmol/I)/22.5) } \\
\text { index scores of <0.46, } \\
0.78-1.22 \text { and }>1.22 \\
\text { had HRs of } 1.48(0.90 \\
\text { to } 2.44), 0.92(0.54 \text { to } \\
1.55) \text { and } 1.96(1.23 \\
\text { to } 3.10) \text { as compared } \\
\text { to those with a } \\
\text { HOMA-IR index of } \\
\text { 0.46-0.77 }\end{array}$ \\
\hline
\end{tabular}

Abbreviations: aHR, adjusted Hazards Ratio; aOR, adjusted Odds Ratio; N/A, not available.

${ }^{\text {a }}$ Adjusted risk ratios are minimally adjusted for age and sex.

${ }^{\mathrm{b}}$ Adjusted for age but not sex.

\subsection{Subgroup and sensitivity analyses}

We performed sensitivity analyses in order to investigate the robustness of pooled estimates to additional adjustment for HCV or HIV coinfection, cirrhosis and DM treatment. After restricting metaanalysis to 16 studies adjusting for HCV coinfection in addition to age and sex (Figure S1), pooled HRs did not change materially. Considering eight studies adjusting for HIV and antiviral treatment (Figure S2), pooled HR from the fixed-effects analysis was attenuated towards the null but remained significant. To investigate the robustness of the association of DM with HCC to adjustment for cirrhosis, a potential mediator, we restricted meta-analysis to studies adjusting for cirrhosis (Figure S3). This did not change pooled HRs materially.

To investigate heterogeneity between type 2 DM and unspecified DM, sensitivity analysis was performed whereby studies were stratified by DM type. Among studies investigating type 2 DM, heterogeneity was $33 \%(p=0.18$ ) (Figure S4). However, this HR did not differ substantially to that observed in the primary meta-analysis.

The association of DM with increased HCC risk was attenuated towards the null in studies that adjusted for metformin use, with risk 

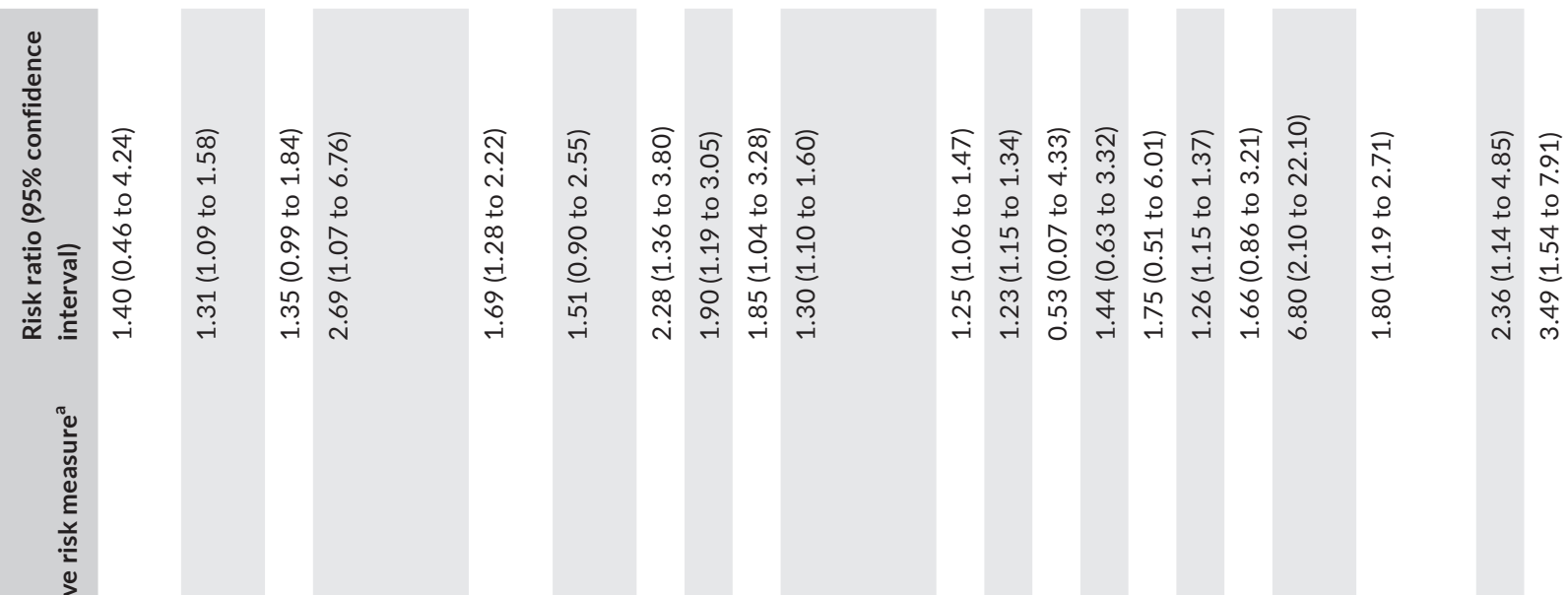

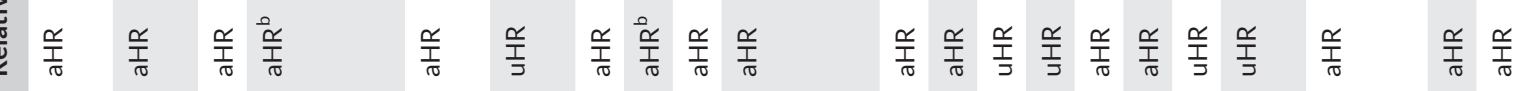
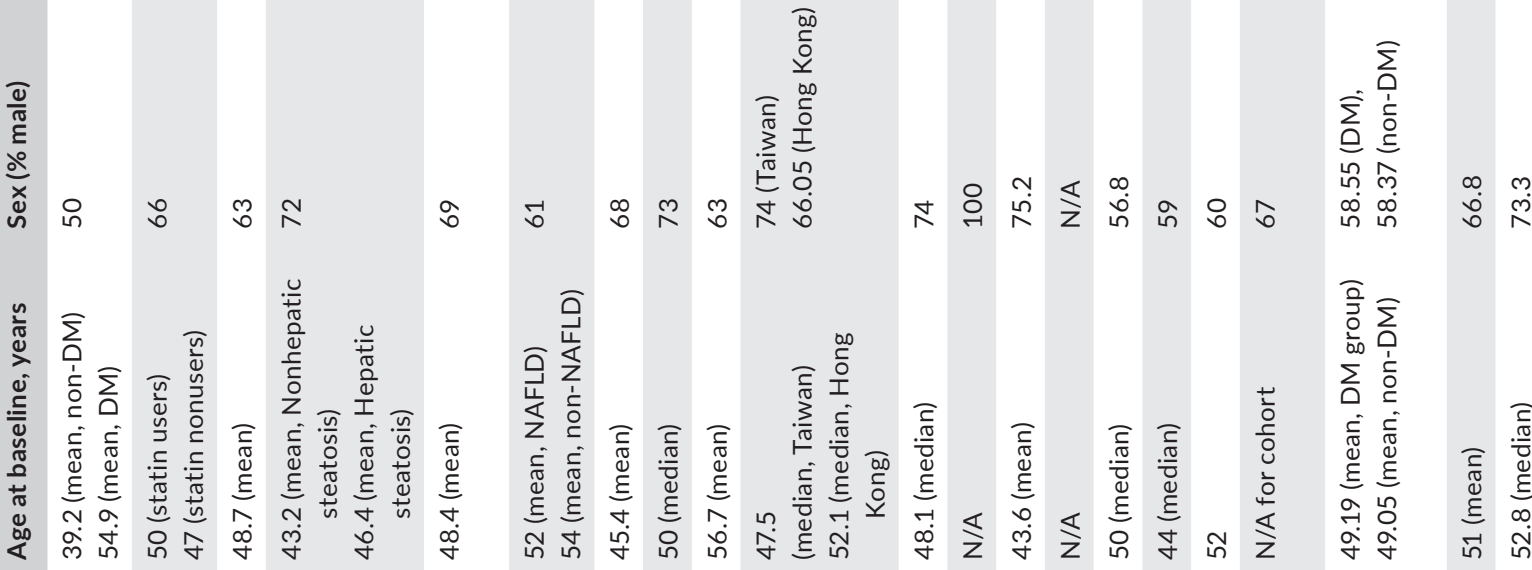

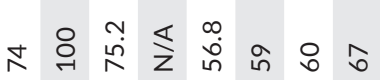

言䔞容

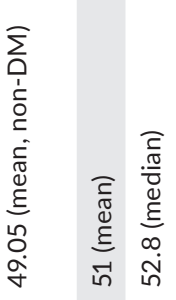

c.

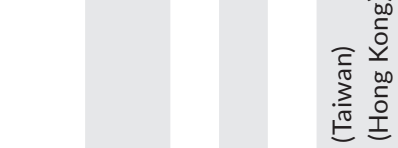

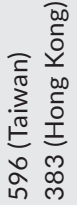

$\sum_{\substack{1 \\ \hline}}$

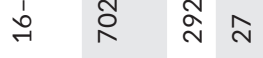

$\stackrel{\infty}{\stackrel{m}{\infty} \infty}$
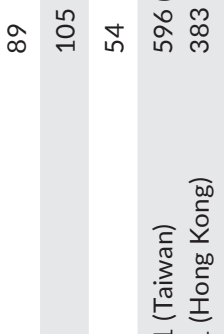

ํํำ



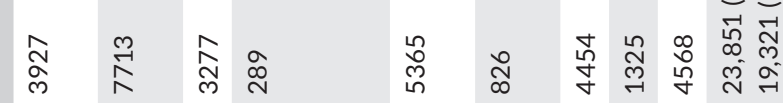

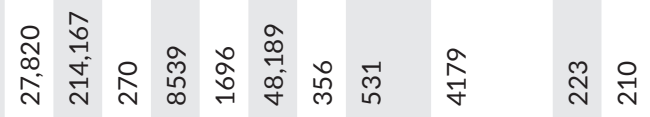

$\stackrel{\substack{-1 \\ \infty}}{\stackrel{\infty}{\infty}}$

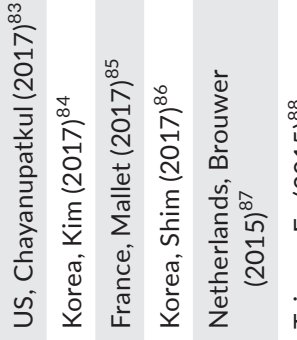

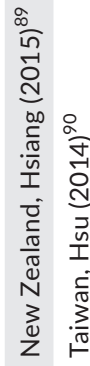




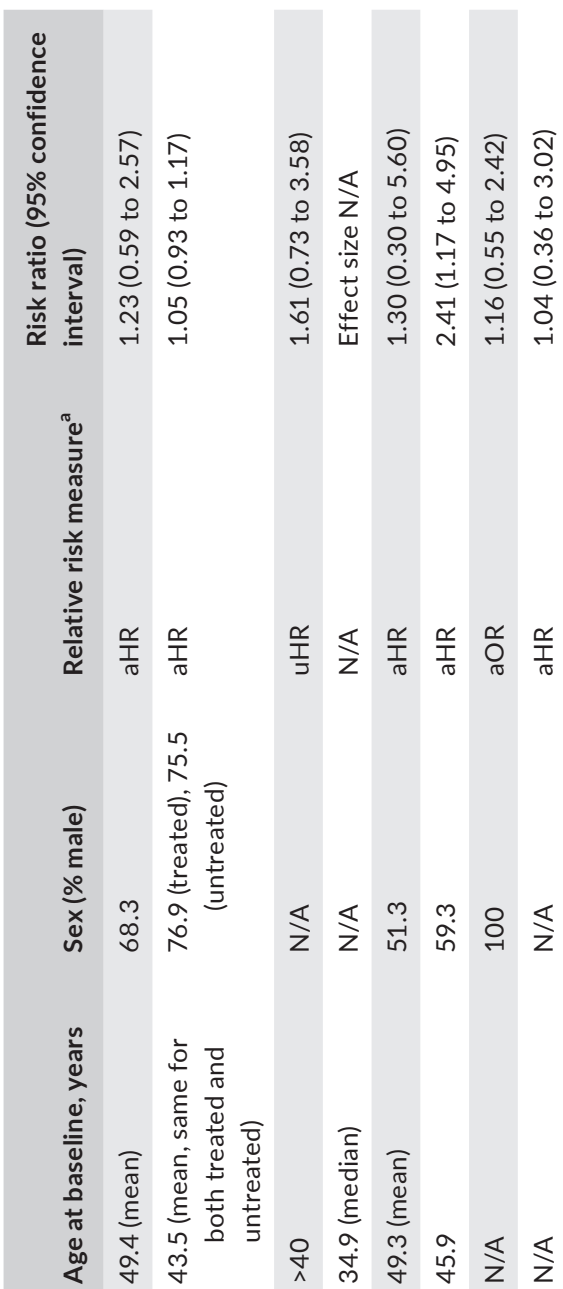

of HCC $16 \%$ higher in DM participants as compared to non-DM (random-effects $\mathrm{HR} 1.16,95 \% \mathrm{Cl}$ 1.04-1.29) in analysis restricted to studies adjusting for metformin use (Figure S5). After restricting to studies adjusting to DM treatment, pooled HRs remained statistically significant.

\subsection{Association of hypertension with hepatocellular carcinoma risk}

Eleven studies investigated the association of $\mathrm{HT}$ with risk of $\mathrm{CHB}$ progression to HCC, one case-control study and 10 cohort studies (Table 2). All studies were mixed-sex samples in which mean/median age at baseline was $\geq 40$ years (Table S2). Definitions of HT were heterogeneous; most studies ascertained hypertension via record linkage, but others used health assessment or interview. Few studies defined clinical thresholds for hypertension classification. 'Higher' MAP was the primary exposure of interest in the case-control study, for which a threshold was not defined.

Among 10 studies reporting hazards of HCC associated with HT, only four HRs were minimally adjusted for age and sex. Out of three studies which reported significantly increased hazards of HCC associated with $\mathrm{HT}$, two reported unadjusted $\mathrm{HRs}$ and one reported a HR adjusted for age and not sex. Another five studies reported an effect in the same direction, but effect sizes were not statistically significant. Adjusted HRs $>1$ ranged from 1.19 to 1.70 and $<1$ from 0.04 to 0.96 . Adjustment for confounders was poor, with only four HRs minimally adjusted for age and sex.

\subsection{Associations of other comorbidities with hepatocellular carcinoma risk}

Seven studies investigated the association of dyslipidaemia with HCC risk in CHB patients (Table 3). All studies reported reduced risks of HCC in participants with dyslipidaemia as compared to those without; however, only one HR was statistically significant. Clinical definitions of dyslipidaemia were often not reported, and only four studies minimally adjusted for age and sex. Six studies investigated the association of obesity with HCC risk. Clinical definitions of obesity varied greatly, and out of four studies reporting increased risks of HCC with obesity, only one HR was statistically significant.

Three studies investigated the association of statin use with HCC risk in CHB. All studies reported HRs $<1$, and two of these HRs were statistically significant. HRs reported in five studies for HCC risk associated with CVD varied, likely due to the variable definitions of CVD used across studies. Associations for other variables, including respiratory disease and renal disease, were reported by $\leq 2$ studies each.

\section{DISCUSSION}

Our meta-analysis suggests that DM is a risk factor for HCC in CHB-infected individuals, with hazards of HCC substantially higher 
JOURNAL OF VRRL HEPAITIS

Author (Year)

Ferreira et al. (2020)

Goh et al. (2020)

Kim et al. (2020)

Yang et al. (2020)

Tan et al. (2019)

Cheuk-Fung et al. (2018)

Hsu et al. (2018)

Hsu et al. (2018)

Kim et al. (2018)

Kim et al. (2017)

Mallet et al. (2017)

Fu et al. (2015)

Hsiang et al. (2015)

Hsu et al. (2014)

Kim et al. (2014)

Wu et al. (2014)

Wang et al. (2009)

Chen et al. (2008)

Lai et al. (2006)
Participants HCC cases

$\begin{array}{rr}3927 & . \\ 7713 & 702 \\ 3277 & 292 \\ 5365 & 378 \\ 4454 & 89 \\ 4568 & 54 \\ 43172 & 979 \\ 27820 & 802 \\ 214167 & 11241 \\ 1696 & 24 \\ 48189 & 3145 \\ 4179 & 111 \\ 223 & 36 \\ 210 & 35 \\ 306 & 45 \\ 43190 & 5446 \\ 696 & 24 \\ 3931 & 187 \\ 6545 & 46\end{array}$

Fixed effect model

Random effects model

Heterogeneity: $I^{2}=52 \%, \tau^{2}=0.0142, p<0.01$

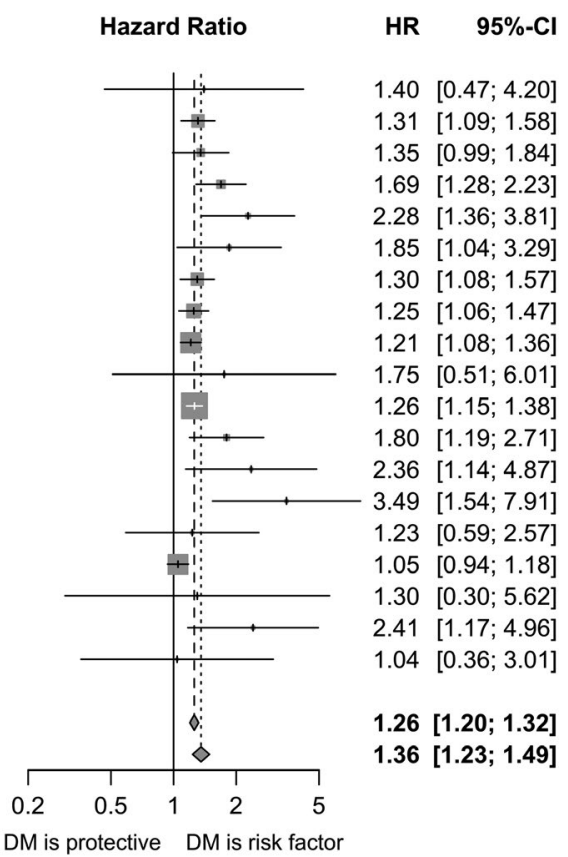

FIGURE 2 Forest plot of hazard ratios from longitudinal cohort studies investigating the association of diabetes mellitus with risk of progression of chronic hepatitis B infection to hepatocellular carcinoma (HCC). All studies included in meta-analysis were cohort or nested case-control studies reporting hazards ratios minimally adjusted for age and sex. The study by Yu et al ${ }^{96}$ provided an odds ratio and was excluded from the meta-analysis. Dashed vertical lines represent HR based on meta-analysis of all studies by fixed-effect and randomeffects models. The studies for pooling the HR had sufficient quality (quality scores $\geq 5$ ). $\mathrm{Cl}$, confidence interval; DM, diabetes mellitus; HR, hazard ratio

TAB LE 2 Effect estimates for cohort studies investigating the association of hypertension with hepatocellular carcinoma risk

\begin{tabular}{|c|c|c|c|c|c|c|}
\hline Country, Author (Year) & Participants, $\mathrm{n}$ & $\begin{array}{l}\text { HCC Cases, } \\
n\end{array}$ & Age at baseline, years & $\begin{array}{l}\text { Sex }(\% \\
\text { male) }\end{array}$ & $\begin{array}{l}\text { Relative risk } \\
\text { measure }^{a}\end{array}$ & $\begin{array}{l}\text { Risk ratio ( } 95 \% \\
\text { confidence interval) }\end{array}$ \\
\hline Korea, Goh $(2020)^{73}$ & 3927 & $16-19$ & $\begin{array}{l}39.2 \text { (mean, non-DM) } \\
54.9 \text { (mean, DM) }\end{array}$ & 50 & aHR & 1.19 (0.95 to 1.48$)$ \\
\hline $\begin{array}{l}\text { France, Brichler } \\
\qquad(2019)^{98}\end{array}$ & 317 & 27 & 53 (median) & 82 & $\mathrm{uHR}$ & 2.91 (1.33 to 6.35 ) \\
\hline Korea, Cho $(2019)^{77}$ & 826 & 86 & $\begin{array}{l}52 \text { (mean, NAFLD) } \\
54 \text { (mean, non-NAFLD) }\end{array}$ & 61 & $a \mathrm{HR}^{\mathrm{b}}$ & $1.38(0.85$ to 2.24$)$ \\
\hline China, $\operatorname{Tan}(2019)^{78}$ & 4454 & 89 & 45.4 (mean) & 68 & $\mathrm{aHR}$ & 0.96 (0.60 to 1.53$)$ \\
\hline Taiwan, Hsu (2018) ${ }^{54}$ & 27,820 & 802 & 48.1 (median) & 74 & $\mathrm{uHR}$ & 2.13 (1.85 to 2.45$)$ \\
\hline $\begin{array}{l}\text { Hong Kong, Chan } \\
\qquad(2017)^{82}\end{array}$ & 270 & 11 & 43.6 (mean) & 75.2 & $\mathrm{uHR}$ & 2.33 (0.68 to 7.98 ) \\
\hline $\begin{array}{l}\text { US, Chayanupatkul } \\
\qquad(2017)^{83}\end{array}$ & 8539 & 317 & $N / A$ & $N / A$ & $a H R^{b}$ & 3.15 (1.02 to 9.75$)$ \\
\hline Taiwan, Hsu (2014) ${ }^{90}$ & 210 & 35 & 52.8 (median) & 73.3 & $\mathrm{uHR}$ & $1.63(0.74$ to 3.60$)$ \\
\hline Taiwan, Chen (2008) & 3931 & 187 & 45.9 & 59.3 & $\mathrm{aHR}$ & 0.45 (0.16 to 1.21$)$ \\
\hline
\end{tabular}

Abbreviations: aHR, adjusted Hazards Ratio; uHR, unadjusted Hazards Ratio.

${ }^{a}$ Adjusted risk ratios are minimally adjusted for age and sex.

${ }^{\mathrm{b}}$ Adjusted for age but not sex.

${ }^{\mathrm{c} C}$ ase-control study using hospital controls.

in the presence of DM; however, we report significant betweenstudy heterogeneity. This association did not materially change after restriction to studies adjusting for relevant confounders, but did suggest a favourable impact of DM treatment with metformin. Pooled effect estimates remained significant in sensitivity analyses. Few studies investigated other comorbidities, and some 
TAB LE 3 Effect estimates for associations of other comorbidities and metabolic factors with hepatocellular carcinoma risk

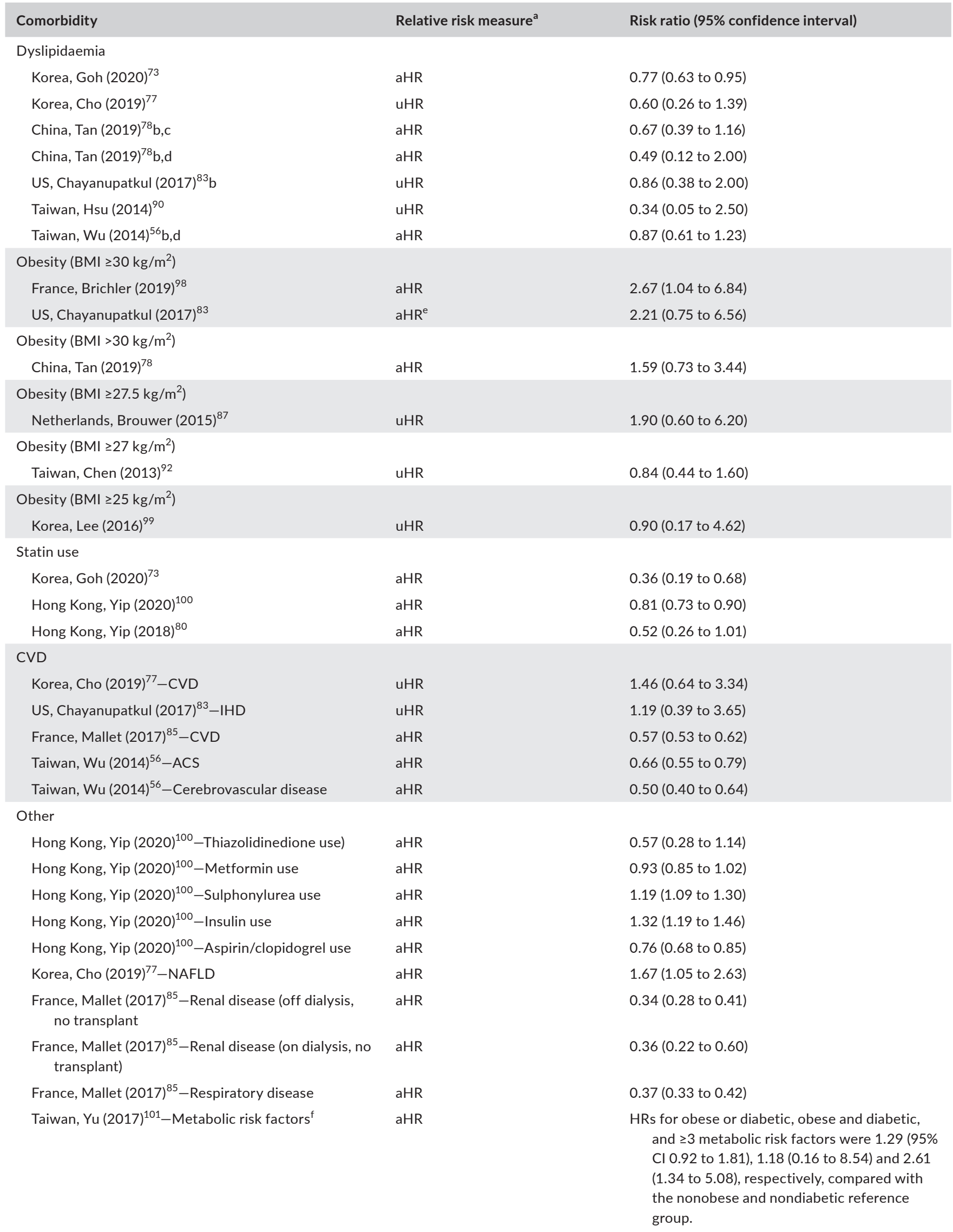


TABLE 3 (Continued)

\begin{tabular}{lll}
\hline Comorbidity & Relative risk measure ${ }^{\text {a }}$ & Risk ratio (95\% confidence interval) \\
\hline Taiwan, Wu $(2014)^{56}-$ COPD & aHR & $0.71(0.59$ to 0.87$)$ \\
Taiwan, Wu $(2014)^{56}-$ Renal failure & aHR & $0.84(0.68$ to 1.04) \\
Taiwan, Chen $(2013)^{92}-$ Metabolic syndrome & uHR & 1.19 (0.63 to 2.26) \\
\hline
\end{tabular}

Abbreviations: ACS, acute coronary syndrome; aHR, adjusted Hazards Ratio; BMI, body mass index; COPD, chronic obstructive pulmonary disease; CVD, cardiovascular disease; IHD, ischaemic heart disease; NAFLD, nonalcoholic fatty liver disease; uHR, unadjusted Hazards Ratio.

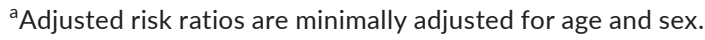

${ }^{b}$ Defined specifically as hyperlipidaemia.

${ }^{\mathrm{c}}$ Defined specifically as hypertriglyceridaemia.

${ }^{\mathrm{d} D e f i n e d ~ s p e c i f i c a l l y ~ a s ~ h y p e r c h o l e s t e r a e m i a . ~}$

${ }^{\mathrm{e}}$ Adjusted for age but not sex.

${ }^{f}$ Metabolic risk factors (obesity, diabetes, hypertriglyceridaemia and HT), with exposure groups split into groups of $0,1,2$ and $\geq 3$ risk factors.

comorbidity search terms included in our systematic literature search returned few or no results. This highlights the need for future investigation of these comorbidities, as antiviral treatment cannot eliminate the risk of HCC entirely and therefore significant risk factors must be identified in order to inform interventions. Although $\mathrm{EASL}^{10}$ and $\mathrm{APASL}^{24}$ guidelines recognize this association, it does not inform surveillance, and is not currently consistently described in other recommendations (eg AASLD guidelines ${ }^{23}$ do not list DM as a risk factor for HCC).

Some studies investigating comorbidities and their metabolic risk factors, specifically dyslipidaemia, reported significantly reduced hazards of $\mathrm{HCC}$ in participants with these conditions compared to those without. This finding was unexpected, and observed associations may be confounded by statin use, as only two of the seven studies reporting significantly reduced hazards of HCC associated with dyslipidaemia adjusted for statin use. Alternatively, $\mathrm{CHB}$ treatment in secondary care may be confounding the analysis, with $\mathrm{CHB}$-infected individuals receiving treatment and HCC screening being potentially more likely to have comorbid dyslipidaemia diagnosed. However, further investigation of this association is warranted to minimize the influence of confounding factors.

Findings from case-control and cohort studies were not consistent; while the majority of cohort studies reported increased hazards of HCC associated with DM, case-control findings were inconsistent, and indeed three studies reported a significant reduction of HCC risk in association with DM. Explanations for such findings include confounding, selection bias associated with the study of hospital control groups that enrich for $\mathrm{DM},{ }^{31,32}$ and chance, especially in small studies. ${ }^{31-34}$

Our findings are consistent with a previous meta-analysis ${ }^{35}$; we provide a comprehensive review of all cohort studies and include a larger number of studies. We restricted our analysis to studies reporting HRs minimally adjusted for age and sex. However, adjustment for covariates and inclusion criteria varied considerably between studies, and this may explain some of the between-study heterogeneity. Substantial heterogeneity remained in sensitivity analyses restricted to studies adjusting for additional key confounders, as adjustment for confounders was variable within these studies and populations may not have been comparable. Although baseline age and sex characteristics were comparable across studies, there was variability regarding exclusion of those with additional comorbidities and those on antiviral treatment.

We noted variable definitions of DM, with some studies restricting investigation to type 2 DM, whereas others included participants with unspecified DM. Risk factors for types 1 and 2 diabetes mellitus vary, and heterogeneity in DM definitions could therefore contribute to variable study populations and outcomes. Global prevalence and incidence estimates for specific DM types do not exist, as distinguishing between types often requires expensive laboratory resources that are not available in many settings. However, most cases of type 1 DM are found in Europe and North America, and the large majority of studies included in this systematic review and meta-analysis were conducted in Asian countries. $^{36}$

Although HRs did not significantly vary with length of follow-up in sensitivity analysis, it is possible that variable lengths of follow-up also contributed to between-study heterogeneity. Generally, cancer is a chronic disease with a slow development, and preclinical disease can be present for many years before clinical manifestation; follow-up periods $<10$ years may be insufficient to detect HCC outcomes. We were unable to provide effect estimates across most potential patient subgroups because the subgroups contained small numbers of studies, putting subgroup analyses at greater risk of chance findings as well as being subject to the influence of multiple testing.

The association of DM with HCC we report in this meta-analysis is weaker than those observed in patients with chronic HCV infection. In studies of individuals with chronic HCV infection, risk of $\mathrm{HCC}$ was elevated $\sim$ twofold in the presence of DM. ${ }^{37,38}$ Previous studies also report increased risks of DM in HCV-infected individuals as compared to noninfected individuals. ${ }^{39-42}$ However, this may be due to the various extra-hepatic manifestations of HCV which are not so clearly associated in HBV infection. ${ }^{43,44}$

In sensitivity analysis restricted to studies adjusting for cirrhosis, the observed association of DM with HCC was attenuated towards the null. This may be explained by a confounding of the association by cirrhosis, accounted for by an independent association of cirrhosis 
with both DM and HCC, and the absence of cirrhosis from the causal pathway that associates DM with HCC. However, if cirrhosis is located along this causal pathway, then it can be characterized as a mediator rather than a confounder. If cirrhosis is a mediator, then adjusting for it would be incorrect.

Past studies support a positive association of DM with HCC risk in non- $\mathrm{CHB}$ patients, ${ }^{6,7,45}$ and aetiological investigation has suggested that DM can lead to cirrhosis and thereby HCC via fatty liver disease, ${ }^{46}$ as a result of accumulation of fatty acids causing oxidative stress driving inflammation and tissue necrosis, ${ }^{47,48}$ and longer-term fibrosis and cirrhosis, thereby increasing HCC risk. However, alternative pathways causally associating DM with HCC have been suggested, including increased hepatocyte proliferation induced by hyperinsulinaemia ${ }^{49,50}$ and production of pro-inflammatory cytokines that increase cell survival via apoptosis inhibition. ${ }^{51-53}$ It is possible that multiple disease pathways associating DM with HCC operate simultaneously. Elucidation of the aetiological mechanisms underpinning this association will inform future epidemiological studies and disease management. Characterizing the impact of glycaemic control on HCC risk is also an important question for future research.

Three studies adjusted for metformin use, ${ }^{54-56}$ and in sensitivity analysis restricted to these studies, the association between DM and HCC remained significant but was attenuated towards the null. It is not known the extent to which this is a result of glucoregulation by metformin, accomplished by inhibition of hepatic gluconeogenesis and improvement of insulin sensitivity in tissues leading to reduced oxidative stress in the liver, ${ }^{57}$ and/or a direct impact of metformin in reducing cancer risk via regulation of cellular signalling. Evidence from observational studies ${ }^{58-60}$ and randomized controlled trials $(R C T s)^{61}$ supports a protective effect of metformin against the development and progression of cancer in diabetic individuals. There is also some RCT evidence for protective effects of metformin against progression of certain cancer types in nondiabetic individuals ${ }^{62}$ although this is not consistent. Multiple large-scale phase III RCTs are currently underway ${ }^{63-66}$ and will provide further information regarding the roles of DM and metformin in cancer development.

We included all studies investigating the association of comorbidities with risk of $\mathrm{CHB}$ progression to $\mathrm{HCC}$ that minimally adjusted for age and sex in order to provide a comprehensive review of available evidence. However, few studies investigated non-DM comorbidities, preventing meta-analysis for these comorbidities. Additionally, we were unable to restrict our meta-analysis of DM and HCC to studies adjusting for further confounders in addition to age and sex, as few studies minimally adjusted for all relevant factors. Publication bias may influence the outcome, as we restricted our search to the peer-reviewed English-language literature, and studies that do not report an association of DM with HCC may be less likely to be published. Our results may not be generalizable to the global $\mathrm{CHB}$ population, as there were a limited number of studies from non-Asian countries. The lack of studies from any African countries is of concern, given that the region carries both the highest HBV prevalence ${ }^{67}$ and largest mortality burdens for cirrhosis and HCC. ${ }^{68,69}$
Our finding that DM is a risk factor for $\mathrm{HCC}$ in $\mathrm{CHB}$-infected individuals suggests that enhanced cancer surveillance may be justified in patients with $\mathrm{CHB}$ and DM to enable early detection and treatment. Improvements in guidelines could help to inform more consistent approaches to risk reduction. After adjustment for metformin use, this association remained significant but was attenuated, suggesting a potential benefit of metformin that warrants further study. Ongoing investigation is required in order to identify and characterize risk factors for HCC, to extend these analyses to diverse global populations and to elucidate disease mechanisms in order to inform prevention, screening and therapeutic intervention.

\section{ACKNOWLEDGEMENTS}

CC acknowledges doctoral funding from GlaxoSmithKline and thanks lain A Gillespie (GlaxoSmithKline UK) for his contributions to this study.

\section{DATA AVAILABILITY STATEMENT}

Data sharing not applicable to this article as no data sets were generated during the current study; all data were obtained from published articles.

\section{ORCID}

Cori Campbell (D) https://orcid.org/0000-0001-5890-7105

Tingyan Wang (D) https://orcid.org/0000-0002-8351-9494

Anna L. McNaughton (D) https://orcid.org/0000-0002-7436-8727

Eleanor Barnes (D) https://orcid.org/0000-0002-0860-0831

Philippa C. Matthews (D) https://orcid.org/0000-0002-4036-4269

\section{REFERENCES}

1. Hepatitis B Fact Sheet. https://www.who.int/news-room/factsheets/detail/hepatitis-b. Published 2019. Accessed December 18, 2019.

2. Stanaway JD, Flaxman AD, Naghavi M, et al. The global burden of viral hepatitis from 1990 to 2013: findings from the Global Burden of Disease Study 2013. Lancet. 2016;388(10049):1081-1088. https://doi.org/10.1016/S0140-6736(16)30579-7

3. Fitzmaurice $\mathrm{C}$, Akinyemiju T, Abera $\mathrm{S}$, et al. The burden of primary liver cancer and underlying etiologies from 1990 to 2015 at the global, regional, and national level results from the global burden of disease study 2015. JAMA Oncol. 2017;3(12):1683-1691. https:// doi.org/10.1001/jamaoncol.2017.3055

4. Simon TG, King LY, Chong DQ, et al. Diabetes, metabolic comorbidities, and risk of hepatocellular carcinoma: results from two prospective cohort studies. Hepatology. 2018;67(5):1797-1806. https://doi.org/10.1002/hep.29660

5. Yang WS, Va P, Bray F, et al. The role of pre-existing diabetes mellitus on hepatocellular carcinoma occurrence and prognosis: a meta-analysis of prospective cohort studies. PLoS One. 2011;6(12):e27326. https://doi.org/10.1371/journal.pone.0027326

6. Hassan MM, Curley SA, Li D, et al. Association of diabetes duration and diabetes treatment with the risk of hepatocellular carcinoma. Cancer. 2010;116(8):1938-1946. https://doi.org/10.1002/ cncr.24982

7. Davila JA, Morgan RO, Shaib Y, McGlynn KA, El-Serag HB. Diabetes increases the risk of hepatocellular carcinoma in the United States: a population based case control study. Gut. 2005;54(4):533-539. https://doi.org/10.1136/gut.2004.052167 
8. Turati F, Talamini R, Pelucchi C, et al. Metabolic syndrome and hepatocellular carcinoma risk. Br J Cancer. 2013;108(1):222-228. https://doi.org/10.1038/bjc.2012.492

9. Borena W, Strohmaier S, Lukanova A, et al. Metabolic risk factors and primary liver cancer in a prospective study of 578,700 adults. Int J Cancer. 2012;131(1):193-200. https://doi.org/10.1002/ ijc. 26338

10. EASL. European Association for the Study of the Liver (EASL) 2017 Clinical Practice Guidelines on the management of hepatitis B virus infection. J Hepatol. 2017;67(2):370-398. https://doi. org/10.1016/j.jhep.2017.03.021

11. Global Report on Diabetes. Geneva; 2016. http://www.who.int/ about/licensing/copyright_form/index.html. Accessed February 24, 2020.

12. GBD Chronic Kidney Disease Collaboration. Global, regional, and national burden of chronic kidney disease, 1990-2017: a systematic analysis for the Global Burden of Disease Study 2017. Lancet. 2020;395(10225):709-733. https://doi.org/10.1016/S0140 $-6736(20) 30045-3$

13. Forouzanfar $\mathrm{MH}$, Liu $\mathrm{P}$, Roth $\mathrm{GA}$, et al. Global burden of hypertension and systolic blood pressure of at least 110 to $115 \mathrm{mmHg}$, 1990-2015. J Am Med Assoc. 2017;317(2):165-182. https://doi. org/10.1001/jama.2016.19043

14. Bansilal S, Castellano JM, Fuster V. Global burden of CVD: focus on secondary prevention of cardiovascular disease. Int J Cardiol. 2015;201:S1-S7. https://doi.org/10.1016/S0167-5273(15)31026 $-3$

15. Papatheodoridis G, Dalekos G, Sypsa V, et al. PAGE-B predicts the risk of developing hepatocellular carcinoma in Caucasians with chronic hepatitis B on 5-year antiviral therapy. J Hepatol. 2016;64(4):800-806. https://doi.org/10.1016/j. jhep.2015.11.035

16. Lee $\mathrm{MH}$, Yang $\mathrm{HI}$, Liu J, et al. Prediction models of long-term Cirrhosis and hepatocellular carcinoma risk in chronic hepatitis B patients: risk scores integrating host and virus profiles. Hepatology. 2013;58(2):546-554. https://doi.org/10.1002/hep.26385

17. Yang HI, Yuen MF, Chan HLY, et al. Risk estimation for hepatocellular carcinoma in chronic hepatitis B (REACH-B): development and validation of a predictive score. Lancet Oncol. 2011;12(6):568-574 https://doi.org/10.1016/S1470-2045(11)70077-8

18. Wong GLH, Wong VWS. Risk prediction of hepatitis B virus-related hepatocellular carcinoma in the era of antiviral therapy. World J Gastroenterol. 2013;19(39):6515-6522. https://doi.org/10.3748/ wjg.v19.i39.6515

19. Yuen MF, Tanaka Y, Fong DYT, et al. Independent risk factors and predictive score for the development of hepatocellular carcinoma in chronic hepatitis B. J Hepatol. 2009;50(1):80-88. https://doi. org/10.1016/j.jhep.2008.07.023

20. Chan HLY, Hui AY, Wong ML, et al. Genotype $C$ hepatitis B virus infection is associated with an increased risk of hepatocellular carcinoma. Gut. 2004;53(10):1494-1498. https://doi.org/10.1136/ gut.2003.033324

21. Chan HLY, Tse $\mathrm{CH}, \mathrm{Mo}$ F, et al. High viral load and hepatitis $B$ virus subgenotype $\mathrm{Ce}$ are associated with increased risk of hepatocellular carcinoma. J Clin Oncol. 2008;26(2):177-182. https://doi. org/10.1200/JCO.2007.13.2043

22. Wong VWS, Chan SL, Mo F, et al. Clinical scoring system to predict hepatocellular carcinoma in chronic hepatitis B carriers. J Clin Oncol. 2010;28(10):1660-1665. https://doi.org/10.1200/ JCO.2009.26.2675

23. Terrault NA, Lok ASF, McMahon BJ, et al. Update on prevention, diagnosis, and treatment of chronic hepatitis B: AASLD 2018 hepatitis B guidance. Hepatology. 2018;67(4):1560-1599. https://doi. org/10.1002/hep. 29800
24. Sarin SK, Kumar M, Lau GK, et al. Asian-Pacific clinical practice guidelines on the management of hepatitis B: a 2015 update. Hepatol Int. 2015;2072(10):1-98. https://doi.org/10.1007/s1207 2-015-9675-4

25. Saraei P, Asadi I, Kakar MA, Moradi-Kor N. The beneficial effects of metformin on cancer prevention and therapy: a comprehensive review of recent advances. Cancer Manag Res. 2019;11:32953313. https://doi.org/10.2147/CMAR.S200059

26. Chae YK, Arya A, Malecek MK, et al. Repurposing metformin for cancer treatment: current clinical studies. Oncotarget. 2016;7(26):4076740780. https://doi.org/10.18632/oncotarget.8194

27. Liberati A, Altman DG, Tetzlaff J, et al. The PRISMA statement for reporting systematic reviews and meta-analyses of studies that evaluate healthcare interventions: explanation and elaboration. BMJ. 2009;339: https://doi.org/10.1136/bmj.b2700

28. Balduzzi S, Rücker G, Schwarzer G. How to perform a meta-analysis with R: a practical tutorial. Evid Based Ment Health. 2019;22(4):153160. https://doi.org/10.1136/ebmental-2019-300117

29. Wells G, Shea B, O'Connell D, et al.The Newcastle-Ottawa Scale (NOS) for assessing the quality of nonrandomised studies in meta-analyses. http://www.ohri.ca/programs/clinical_epidemiology/ oxford.asp. Accessed June 17, 2020.

30. Ferreira G, Stuurman AL, Horsmans Y, et al. Hepatitis B virus infection and the risk of liver disease progression in type 2 diabetic patients with potential nonalcoholic fatty liver disease. Eur J Gastroenterol Hepatol. 2020;32(1):101-109. https://doi. org/10.1097/MEG.0000000000001537

31. Li Q, Li W-W, Yang X, et al. Type 2 diabetes and hepatocellular carcinoma: a case-control study in patients with chronic hepatitis B. Int J Cancer. 2012;131(5):1197-1202. https://doi.org/10.1002/ ijc. 27337

32. Gao C, Fang L, Zhao HC, Li JT, Yao SK. Potential role of diabetes mellitus in the progression of cirrhosis to hepatocellular carcinoma: a cross-sectional case-control study from Chinese patients with HBV infection. Hepatobiliary Pancreat Dis Int. 2013;12(4):385393. https://doi.org/10.1016/S1499-3872(13)60060-0

33. Kennedy K, Graham SM, Arora N, Shuhart MC, Kim HN. Hepatocellular carcinoma among US and non- US-born patients with chronic hepatitis B: risk factors and age at diagnosis. PLoS One. 2018;13(9): https://doi.org/10.1371/journ al.pone.0204031

34. Chao LT, Wu CF, Sung FY, et al. Insulin, glucose and hepatocellular carcinoma risk in male hepatitis B carriers: results from 17year follow-up of a population-based cohort. Carcinogenesis. 2011;32(6):876-881. https://doi.org/10.1093/carcin/bgr058

35. Tan Y, Wei S, Zhang W, Yang J, Yang J, Yan L. Type 2 diabetes mellitus increases the risk of hepatocellular carcinoma in subjects with chronic hepatitis B virus infection: A meta-analysis and systematic review. Cancer Manag Res. 2019;11:705-713. https://doi. org/10.2147/CMAR.S188238

36. World Health Organisation. Global Report on Diabetes. Geneva; 2016. http://www.who.int/about/licensing/copyright_form/ index.html. Accessed June 4, 2020.

37. Lai SW, Chen PC, Liao KF, Muo CH, Lin CC, Sung FC. Risk of hepatocellular carcinoma in diabetic patients and risk reduction associated with anti-diabetic therapy: a population-based cohort study. Am J Gastroenterol. 2012;107(1):46-52. https://doi.org/10.1038/ ajg.2011.384

38. Veldt BJ, Chen W, Heathcote EJ, et al. Increased risk of hepatocellular carcinoma among patients with hepatitis $C$ cirrhosis and diabetes mellitus. Hepatology. 2008;47(6):1856-1862. https://doi. org/10.1002/hep.22251

39. Antonelli A, Ferri C, Fallahi P, et al. Hepatitis C virus infection: evidence for an association with type 2 diabetes. Diabetes 
Care. 2005;28(10):2548-2550. https://doi.org/10.2337/diaca re.28.10.2548

40. Grimbert S, Valensi P, Lévy-Marchal C, et al. High prevalence of diabetes mellitus in patients with chronic hepatitis $\mathrm{C}$. a case-control study. Gastroenterol Clin Biol. 1996;20(6-7):544-548. https:// pubmed.ncbi.nlm.nih.gov/8881566/?dopt=Abstract. Accessed June 8, 2020.

41. Mehta SH, Brancati FL, Strathdee SA, et al. Hepatitis $C$ virus infection and incident type 2 diabetes. Hepatology. 2003;38(1):50-56. https://doi.org/10.1053/jhep.2003.50291

42. Mehta SH, Brancati FL, Sulkowski MS, Strathdee SA, Szklo M, Thomas DL. Prevalence of type 2 diabetes mellitus among persons with hepatitis $C$ virus infection in the United States. Ann Intern Med. 2000;133(8):592-599. https://doi.org/10.7326/0003-4819133-8-200010170-00009

43. Sherman AC, Sherman KE. Extrahepatic manifestations of hepatitis Cinfection: navigating CHASM. Curr HIV/AIDS Rep. 2015;12(3):353361. https://doi.org/10.1007/s11904-015-0274-8

44. Cacoub P, Comarmond C, Domont F, Savey L, Desbois AC, Saadoun D. Extrahepatic manifestations of chronic hepatitis C virus infection. Ther Adv Infect Dis. 2016;3(1):3-14. https://doi. org/10.1177/2049936115585942

45. Donadon V, Balbi M, Mas MD, Casarin P, Zanette G. Metformin and reduced risk of hepatocellular carcinoma in diabetic patients with chronic liver disease. Liver Int. 2010;30(5):750-758. https:// doi.org/10.1111/j.1478-3231.2010.02223.x

46. Mantovani A, Targher G. Type 2 diabetes mellitus and risk of hepatocellular carcinoma: spotlight on nonalcoholic fatty liver disease. Ann Transl Med. 2017;5(13): https://doi.org/10.21037/ atm.2017.04.41

47. Di Bisceglie AM. What every hepatologist should know about endocrinology: obesity, diabetes, and liver disease. Gastroenterology. 2004;126(2):604-606. https://doi.org/10.1053/j. gastro.2003.12.018

48. Garcia-Compean D, Jacquez-Quintana JO, Gonzalez-Gonzalez JA, Maldonado-Garza H. Liver cirrhosis and diabetes: risk factors, pathophysiology, clinical implications and management. World J Gastroenterol. 2009;15(3):280-288. https://doi.org/10.3748/ wjg.15.280

49. Moore MA, Park CB, Tsuda H. Implications of the hyperinsulinaemia-diabetes-cancer link for preventive efforts. Eur J Cancer Prev. 1998;7(2):89-107. https://pubmed.ncbi.nlm.nih.gov/9818771/. Accessed June 5, 2020.

50. Calle EE, Kaaks R. Overweight, obesity and cancer: epidemiological evidence and proposed mechanisms. Nat Rev Cancer. 2004;4(8):579-591. https://doi.org/10.1038/nrc1408

51. Garg SK, Maurer H, Reed K, Selagamsetty R. Diabetes and cancer: two diseases with obesity as a common risk factor. Diabetes, Obes Metab. 2014;16(2):97-110. https://doi.org/10.1111/dom.12124

52. Park EJ, Lee JH, Yu GY, et al. Dietary and genetic obesity promote liver inflammation and tumorigenesis by enhancing IL-6 and TNF expression. Cell. 2010;140(2):197-208. https://doi.org/10.1016/j. cell.2009.12.052

53. Ali Kamkar MM, Ahmad R, Alsmadi O, Behbehani K. Insight into the impact of diabetes mellitus on the increased risk of hepatocellular carcinoma: mini-review. J Diabetes Metab Disord. 2014;13(1):57. https://doi.org/10.1186/2251-6581-13-57

54. Hsu YC, Ho HJ, Lee TY, et al. Temporal trend and risk determinants of hepatocellular carcinoma in chronic hepatitis $B$ patients on entecavir or tenofovir. J Viral Hepat. 2018;25(5):543-551. https://doi. org/10.1111/jvh.12832

55. Kim K, Choi S, Park SM. Association of fasting serum glucose level and type 2 diabetes with hepatocellular carcinoma in men with chronic hepatitis B infection: a large cohort study. Eur J Cancer. 2018;102:103-113. https://doi.org/10.1016/j.ejca.2018.07.008
56. Wu CY, Lin JT, Ho HJ, et al. Association of nucleos(T)ide analogue therapy with reduced risk of hepatocellular carcinoma in patients with chronic hepatitis B - a nationwide cohort study. Gastroenterology. 2014;147(1): https://doi.org/10.1053/j. gastro.2014.03.048

57. Foretz M, Guigas B, Viollet B. Understanding the glucoregulatory mechanisms of metformin in type 2 diabetes mellitus. Nat Rev Endocrinol. 2019;15(10):569-589. https://doi.org/10.1038/s4157 4-019-0242-2

58. He X, Esteva FJ, Ensor J, Hortobagyi GN, Lee M-H, Yeung S-CJ. Metformin and thiazolidinediones are associated with improved breast cancer-specific survival of diabetic women with HER2+ breast cancer. Ann Oncol. 2012;23(7):1771-1780. https://www. ncbi.nlm.nih.gov/pmc/articles/PMC3387820/. Accessed June 8, 2020.

59. Lee JH, II KT, Jeon SM, Hong SP, Cheon JH, Kim WH. The effects of metformin on the survival of colorectal cancer patients with diabetes mellitus. Int J Cancer. 2012;131(3):752-759. https://doi. org/10.1002/ijc.26421

60. Evans JMM, Donnelly LA, Emslie-Smith AM, Alessi DR, Morris AD. Metformin and reduced risk of cancer in diabetic patients. Br Med J. 2005;330(7503):1304-1305. https://doi.org/10.1136/ bmj.38415.708634.F7

61. Landman GWD, Kleefstra N, Van Hateren KJJ, Groenier KH, Gans ROB, Bilo HJG. Metformin associated with lower cancer mortality in type 2 diabetes: Zodiac-16. Diabetes Care. 2010;33(2):322-326. https://doi.org/10.2337/dc09-1380

62. Higurashi T, Hosono K, Takahashi H, et al. Metformin for chemoprevention of metachronous colorectal adenoma or polyps in post-polypectomy patients without diabetes: a multicentre double-blind, placebo-controlled, randomised phase 3 trial. Lancet Oncol. 2016;17(4):475-483. https://doi.org/10.1016/S1470 $-2045(15) 00565-3$

63. Neoadjuvant Chemotherapy With or Without Metformin in Early Breast Cancer. - Full Text View - ClinicalTrials.gov. https://www.clinicaltrials.gov/ct2/show/NCT04387630?ter$\mathrm{m}=$ metformin\&recrs=abdf\&type $=\operatorname{lnt}$ \& \& cond=cancer\&phase $=23 \& d r a w=2 \&$ rank=5. Accessed June 8, 2020.

64. The Metformin Active Surveillance Trial (MAST) Study.- Full Text View - ClinicalTrials.gov. https://www.clinicaltrials.gov/ct2/ show $/$ NCT01864096? term $=$ metformin\&recrs $=$ abdf\&type $=$ In $\operatorname{tr} \&$ cond $=$ cancer\&phase $=23 \& d r a w=2 \&$ rank $=6$. Accessed June 8 , 2020.

65. A Phase III Randomized Trial of Metformin vs Placebo in Early Stage Breast Cancer. - Full Text View - ClinicalTrials.gov. https://www.clinicaltrials.gov/ct2/show/NCT01101438?ter$\mathrm{m}=\mathrm{metformin} \& \mathrm{recrs}=\mathrm{abdf} \&$ type $=\ln \mathrm{tr} \&$ cond $=$ cancer\&phase $=23 \& d r a w=2 \&$ rank=3. Accessed June 8, 2020.

66. U.S. National Library of Medicine. https://www.clinicaltrials.gov/ ct2/home. Accessed June 8, 2020.

67. Global Hepatitis Report. Geneva; 2017. https://apps.who.int/iris/ bitstream/handle/10665/255016/9789241565455-eng.pdf. Accessed July 6, 2020.

68. Yang JD, Hainaut P, Gores GJ, Amadou A, Plymoth A, Roberts LR. A global view of hepatocellular carcinoma: trends, risk, prevention and management. Nat Rev Gastroenterol Hepatol. 2019;16(10):589604. https://doi.org/10.1038/s41575-019-0186-y

69. Sepanlou SG, Safiri S, Bisignano C, et al. The global, regional, and national burden of cirrhosis by cause in 195 countries and territories, 1990-2017: a systematic analysis for the Global Burden of Disease Study 2017. Lancet Gastroenterol Hepatol. 2020;5(3):245-266. https://doi.org/10.1016/S2468 $-1253(19) 30349-8$

70. Shyu Y, Huang T, Chien C, Yeh C, Lin C, Chien R. Diabetes poses a higher risk of hepatocellular carcinoma and mortality in patients 
with chronic hepatitis B: a population-based cohort study. J Viral Hepat. 2019;26(6):718-726. https://doi.org/10.1111/jvh.13077

71. Li X, Xu H, Gao P. Diabetes mellitus is a risk factor for hepatocellular carcinoma in patients with chronic hepatitis $B$ virus infection in China. Med Sci Monit. 2018;24:6729-6734. https://doi. org/10.12659/MSM.911702

72. Han H, Deng H, Han T, Zhao H, Hou F, Qi X. Association between hepatocellular carcinoma and type 2 diabetes mellitus in Chinese hepatitis B virus cirrhosis patients: a case-control study. Med Sci Monit. 2017;23:3324-3334. https://doi.org/10.12659/ MSM. 902440

73. Goh MJ, Sinn DH, Kim S, et al. Statin use and the risk of hepatocellular carcinoma in patients with chronic hepatitis B. Hepatology. 2020;71(6):2023-2032. https://doi.org/10.1002/hep. 30973

74. Kim SU, Seo YS, Lee HA, et al. Validation of the CAMD score in patients with chronic hepatitis $B$ virus infection receiving antiviral therapy. Clin Gastroenterol Hepatol. 2020;18(3):693-699.e1. https://doi.org/10.1016/j.cgh.2019.06.028

75. Lim CT, Goh GBB, Li H, et al. Presence of hepatic steatosis does not increase the risk of hepatocellular carcinoma in patients with chronic hepatitis B over long follow-up. Microbiol Insights. 2020;13:117863612091887. https://doi.org/10.1177/1178636120 918878

76. Yang HI, Yeh ML, Wong GL, et al. Real-World Effectiveness From the Asia Pacific Rim Liver Consortium for HBV Risk Score for the Prediction of Hepatocellular Carcinoma in Chronic Hepatitis B Patients Treated With Oral Antiviral Therapy. J Infect Dis. 2020;221(3):389-399. https://pubmed.ncbi.nlm.nih.gov/31550 363/. Accessed July 1, 2020.

77. Cho $\mathrm{H}$, Chang $\mathrm{Y}$, Lee $\mathrm{JH}$, et al. Radiologic nonalcoholic fatty liver disease increases the risk of hepatocellular carcinoma in patients with suppressed chronic hepatitis B. J Clin Gastroenterol. 2020;54(7):633-641. https://doi.org/10.1097/MCG.0000000000 001217.

78. Tan $\mathrm{Y}$, Zhang $\mathrm{X}$, Zhang $\mathrm{W}$, et al. The influence of metabolic syndrome on the risk of hepatocellular carcinoma in patients with chronic hepatitis B infection in mainland China. Cancer Epidemiol Biomarkers Prev. 2019;28(12):2038-2046. https://doi. org/10.1158/1055-9965.EPI-19-0303

79. Wang H-W, Lai H-C, Hu T-H, et al. Stratification of hepatocellular carcinoma risk through modified FIB-4 index in chronic hepatitis B patients on entecavir therapy. J Gastroenterol Hepatol. 2019;34(2):442-449. https://doi.org/10.1111/jgh.14372

80. Cheuk-Fung Yip T, Wai-Sun Wong V, Lik-Yuen Chan $\mathrm{H}$, et al. Effects of diabetes and glycemic control on risk of hepatocellular carcinoma after seroclearance of hepatitis B surface antigen. Clin Gastroenterol Hepatol. 2018;16(5):765-773.e2. https://doi. org/10.1016/j.cgh.2017.12.009

81. Hsu YC, Yip TCF, Ho HJ, et al. Development of a scoring system to predict hepatocellular carcinoma in Asians on antivirals for chronic hepatitis B. J Hepatol. 2018;69(2):278-285. https://doi. org/10.1016/j.jhep.2018.02.032

82. Chan AWH, Wong GLH, Chan H-Y, et al. Concurrent fatty liver increases risk of hepatocellular carcinoma among patients with chronic hepatitis B. J Gastroenterol Hepatol. 2017;32(3):667-676. https://doi.org/10.1111/jgh.13536

83. Chayanupatkul M, Omino R, Mittal S, et al. Hepatocellular carcinoma in the absence of cirrhosis in patients with chronic hepatitis B virus infection. J Hepatol. 2017;66(2):355-362. https://doi. org/10.1016/j.jhep.2016.09.013

84. Kim JH, Sinn DH, Gwak G-Y, et al. Insulin resistance and the risk of hepatocellular carcinoma in chronic hepatitis B patients. J Gastroenterol Hepatol. 2017;32(5):1100-1106. https://doi. org/10.1111/jgh.13647
85. Mallet V, Hamed K, Schwarzinger M. Prognosis of patients with chronic hepatitis B in France (2008-2013): a nationwide, observational and hospital-based study. J Hepatol. 2017;66(3):514-520. https://doi.org/10.1016/j.jhep.2016.10.031

86. Shim JJ, Oh CH, Kim JW, Lee CK, Kim BH. Liver cirrhosis stages and the incidence of hepatocellular carcinoma in chronic hepatitis B patients receiving antiviral therapy. Scand J Gastroenterol. 2017;52(9):10291036. https://doi.org/10.1080/00365521.2017.1335773

87. Brouwer WP, van der Meer AJ, Boonstra A, et al. The impact of PNPLA3 (rs738409 C>G) polymorphisms on liver histology and long-term clinical outcome in chronic hepatitis B patients. Liver Int. 2015;35(2):438-447. https://doi.org/10.1111/liv.12695

88. Fu S-C, Huang Y-W, Wang T-C, Hu J-T, Chen D-S, Yang S-S. Increased risk of hepatocellular carcinoma in chronic hepatitis B patients with new onset diabetes: a nationwide cohort study. Aliment Pharmacol Ther. 2015;41(11):1200-1209. https://doi. org/10.1111/apt.13191

89. Hsiang JC, Gane EJ, Bai WW, Gerred SJ. Type 2 diabetes: a risk factor for liver mortality and complications in hepatitis B cirrhosis patients. J Gastroenterol Hepatol. 2015;30(3):591-599. https://doi. org/10.1111/jgh.12790

90. Hsu YC, Wu CY, Lane HY, et al. Determinants of hepatocellular carcinoma in cirrhotic patients treated with nucleos $(\mathrm{t})$ ide analogues for chronic hepatitis B. J Antimicrob Chemother. 2014;69(7):19201927. https://doi.org/10.1093/jac/dku041

91. Kim SS, Hwang JC, Lim SG, Ahn SJ, Cheong JY, Cho SW. Effect of virological response to entecavir on the development of hepatocellular carcinoma in hepatitis B viral cirrhotic patients: comparison between compensated and decompensated cirrhosis. Am J Gastroenterol. 2014;109(8):1223-1233. https://doi.org/10.1038/ ajg. 2014.145

92. Chen CT, Chen JY, Wang JH, et al. Diabetes mellitus, metabolic syndrome and obesity are not significant risk factors for hepatocellular carcinoma in an HBV- and HCV-endemic area of Southern Taiwan. Kaohsiung J Med Sci. 2013;29(8):451-459. https://doi. org/10.1016/j.kjms.2012.12.006

93. Walter $\mathrm{SR}$, Thein $\mathrm{H}-\mathrm{H}$, Gidding $\mathrm{HF}$, et al. Risk factors for hepatocellular carcinoma in a cohort infected with hepatitis B or C. J Gastroenterol Hepatol. 2011;26(12):1757-1764. https://doi. org/10.1111/j.1440-1746.2011.06785.x

94. Wang CS, Yao WJ, Chang TT, Wang ST, Chou P. The impact of type 2 diabetes on the development of hepatocellular carcinoma in different viral hepatitis statuses. Cancer Epidemiol Biomarkers Prev. 2009;18(7):2054-2060. https://doi.org/10.1158/1055-9965. EPI-08-1131

95. Chen CL, Yang HI, Yang WS, et al. Metabolic factors and risk of hepatocellular carcinoma by chronic hepatitis B/C infection: a follow-up study in Taiwan. Gastroenterology. 2008;135(1):111-121. https://doi.org/10.1053/j.gastro.2008.03.073

96. Yu MW, Shih WL, Lin CL, et al. Body-mass index and progression of hepatitis B: a population-based cohort study in men. J Clin Oncol. 2008;26(34):5576-5582. https://doi.org/10.1200/ JCO.2008.16.1075

97. Lai MS, Hsieh MS, Chiu YH, Chen THH. Type 2 diabetes and hepatocellular carcinoma: a cohort study in high prevalence area of hepatitis virus infection. Hepatology. 2006;43(6):1295-1302. https://doi.org/10.1002/hep.21208

98. Brichler S, Nahon P, Zoulim F, et al. Non-virological factors are drivers of hepatocellular carcinoma in virosuppressed hepatitis B cirrhosis: results of ANRS CO12 CirVir cohort. J Viral Hepat. 2019;26(3):384-396. https://doi.org/10.1111/jvh.13029

99. Lee J, Yoo SH, Sohn W, et al. Obesity and hepatocellular carcinoma in patients receiving entecavir for chronic Hepatitis B. Clin Mol Hepatol. 2016;22(3):339-349. https://doi.org/10.3350/ cmh.2016.0021 
100. Yip TC, Wong VW, Chan HL, et al. Thiazolidinediones reduce the risk of hepatocellular carcinoma and hepatic events in diabetic patients with chronic hepatitis B. J Viral Hepat. 2020;27(9):904-914. https://doi.org/10.1111/jvh.13307

101. Yu MW, Lin CL, Liu CJ, Yang SH, Tseng YL, Wu CF. Influence of metabolic risk factors on risk of hepatocellular carcinoma and liver-related death in men with chronic hepatitis B: a large cohort study. Gastroenterology. 2017;153(4):1006-1017.e5. https://doi. org/10.1053/j.gastro.2017.07.001

\section{SUPPORTING INFORMATION}

Additional supporting information may be found online in the Supporting Information section.
How to cite this article: Campbell C, Wang T, McNaughton AL, Barnes E, Matthews PC. Risk factors for the development of hepatocellular carcinoma ( $\mathrm{HCC})$ in chronic hepatitis $B$ virus (HBV) infection: a systematic review and meta-analysis. J Viral Hepat. 2021;28:493-507. https://doi.org/10.1111/jvh.13452 